\title{
School District Administrator Perceptions and Hiring Practices of Teachers Who Participated in International Student Teaching Placements
}

\author{
Ann C. Gaudino ${ }^{1 *}$ \\ ${ }^{1}$ Millersville University of Pennsylvania, United States \\ *Correspondence: ann.gaudino@millersville.edu
}

\begin{abstract}
This study investigated school district administrators' perceptions and hiring practices of teachers who participated in international student teaching experiences. Thirty central office administrators from 12 states across the United States were interviewed. The responses and practices of these administrators and the districts that they represent were compared with the perceptions of student teachers and teachers from previous studies who had student taught abroad. Findings reveal that both teachers and administrators believe that there are a multitude of benefits to international student teaching and that this experience ultimately impacts student learning. While they also believe that such experience should be accounted for in the hiring process, very few districts have a formal way of accounting for international student teaching experiences. Recommendations include how districts might adjust their hiring process to account more specifically for the various of experience that teachers bring to their positions.
\end{abstract}

Keywords: student teaching, teacher recruitment, hiring, diversity

\section{Introduction}

This study was designed to investigate school district administrators' perceptions and hiring practices of teachers who participated in international student teaching experiences. International student teaching takes place for a minimum of eight weeks outside of the United States. Thirty central

Received December 24, 2019; revised May 1, 2020; July 2, 2020; accepted August 1, 2020; electronically published March 2 , 2021 
office administrators from 12 states across the United States were interviewed. Administrators included superintendents, assistant superintendents and human resource directors who were directly involved in the hiring process and ultimate decision to hire teachers. The responses and practices of these administrators and the districts that they represent were compared with the perceptions of student teachers and teachers from previous studies who had student taught abroad.

Analysis of the participant administrator narratives provide a holistic picture of ways in which they reflect on the impact of international and diverse student teaching experience. Furthermore, administrator participants concurred that international student teaching experience specifically helps teachers to develop increased personal confidence, cultural awareness, ability to self-reflect on their professional practice and implement change, and ability to differentiate instruction for diverse learners. They also believed that teachers who student taught abroad possess these skills at a greater level than teachers who only student taught in the United States even if those placements were in areas with diversity.

While the student teachers and teachers in previous studies opined that their international student teaching experience was a distinct advantage for them in the hiring process (Bradley, et al., 2009; Kissock \& Richardson, 2009), 29 of the 30 administrators interviewed in this study indicated that their districts have no formal way of accounting for international student teaching experience any differently than student teaching experience in the United States. When asked why their districts do not account specifically for international student teaching experience in the hiring process, all but two struggled to answer the question. However, all indicated that their hiring practices do account for diverse student teaching or diverse teaching experiences that are similar to the diversity currently existing in their districts, but not in a way that differentiates for international placements.

Theoretical Framework and Perspective

This study is grounded in the framework of ethnocentrism and ethnorelativism as presented in Bennett's (2004) Developmental Model of Intercultural Sensitivity (DMIS) (M. Bennett, 1986, 1993; J. 
Bennett, 2003, 2004). DMIS was developed with a Grounded Theory approach (Glaser \& Strauss, 1967;

Strauss \& Corbin, 1990) using theoretical concepts to explain patterns that emerge from systematic observation (M. Bennett, 2004). M. Bennett (2004) described ethnocentrism and ethnorelativisim as existing on a spectrum of six developmental stages of cultural difference experience through which one may progress. Individuals who are ethnocentric rely on their own culture as central to their reality whereas individuals who achieve ethnorelativism experience their "own beliefs and behaviors as just one organization of reality among many viable possibilities" (M. Bennett, 2004, p. 1). The DMIS purports that interaction with cultural difference generates pressure for change in one's worldview because the individual's ethnocentric worldview is inadequate for developing and maintaining new, necessary crosscultural social relations (M. Bennett, 2004). The need for such cross-cultural relations creates a kind of pressure within the person's thinking that urges the person to develop greater competence in intercultural matters. Therefore, experiences, such as international student teaching and teaching with diverse populations, can create this type of pressure and serve as the impetus to expand teachers' worldviews. Moving towards ethnorelativism can then have a long-term effect on professional practice of teachers and the way in which they interact with students and their families.

The perceptions of student teachers demonstrate that they anticipate benefits to student teaching abroad including developing greater global vision and competence (Kissock \& Richardson, 2009; Gaudino, et al., 2012); personal awareness and self-confidence (Bradly, et al., 2009; Kissock \& Richardson, 2009; Martin, 2012; Marx \& Moss, 2011; Stachowski \& Brantmeier, 2002; Wilson, 2009; Wilson \& Flournay, 2007); job opportunities (Bradley, et al., 2009; Kissock \& Richardson, 2009); and increased ability to self-reflect on their professional practice and implement change (Gaudino, et al., 2012).

These student teacher perceptions align with the perceptions of teachers who previously student taught abroad. Bryan and Sprague (1997) were among the first to describe how teachers who 
had previously student taught abroad perceived the effect of that experience. They concluded that the abroad student teaching experience had positive effects for teachers in hiring, retention in teaching, attitudes towards students, attitudes towards a second language, and teaching strategies. Teachers gained respect for individual differences of students and cultural differences and they learned to be flexible in teaching in varied places and with diverse students. Similarly, DeVillar and Jiang (2012) and Gaudino and Wilson (2019) concluded that teachers who previously student taught abroad developed: greater cultural awareness, understanding and ability to differentiate instruction for diverse learners; self-confidence and classroom management skills; ability to self-reflect on professional practice to implement change; and job opportunities.

Teachers in these studies cited specific examples of how each of these gains presented itself in their teaching, except for hiring. As the findings of these studies expressed the perceptions of student teachers and teachers, the question remained about whether administrators actually valued international student teaching in the same way and how, if at all, they formally accounted for it in the hiring process.

Shively and Misco (2012) conducted a mixed methods study with 18 respondent administrators from the 38 largest school districts in one quadrant of a large Midwestern state and concluded that student teaching abroad is a benefit in the hiring process. However, there were several caveats. Specifically, "the burden of proof to demonstrate transferability of this experience to the interviewing school rests with the interviewee" (p. 58). Furthermore, "to a small extent, the country in which the experience was gained matters" (p. 58) and administrators also concurred that a portion of the experience had to be in the United States or "be in a transferable setting to the interviewer's school" (p. 58). Therefore, while Shively and Misco (2012) concluded that international student teaching was a benefit in the hiring process, it was only a benefit under certain circumstances and if the teacher portrayed his or her experience in certain ways. As the participants in this study were from a quadrant of a single state, the question remained whether administrators from other parts of the United States would respond similarly. 
This study was undertaken with central office administrators from a broader array of states in order to answer the research question, "How, if at all, is student teaching abroad accounted for in the hiring process?"

\section{Methods}

\section{Participants}

Members of the American Association of School Personnel Administrators were invited by the author to participate in a survey surrounding district hiring practices. One hundred nine superintendents, assistant superintendents, and human resource directors responded. Several prompts included an option for respondents to participate in follow-up interviews specific to various aspects of hiring. Thirty administrators expressed interest in participating in a follow-up interview about their hiring practices with candidates who have international student teaching and teaching and all 30 completed the interview process. Participant central office administrators were located in the following states: California (4), Florida (3), Michigan (3), New York (3), Pennsylvania (3), Texas (3), Arizona (2), Georgia (2), lowa (2), Massachusetts (2), Illinois (2), and Colorado (1). These interviews provided a broad range of narratives that expressed perspectives of central office administrators who have responsibility for hiring teachers in their districts.

\section{Procedures}

Systematic steps were followed in each interview. The researcher posed the question and, when the participant finished responding to each question, a member check was performed by repeating back to the participant the key points that he or she had raised and requesting his or her suggestions and confirmations (Creswell, 2014; Morse, et al., 2002). In particular, these interviews brought forth a similarity in narratives that expressed the perspectives of the various central office administrators participating in the study. The questions posed to the administrator participants were:

1. How, if at all, does your district account for international student teaching experiences in the hiring process? 
2. Why does or does not your district account for international student teaching experiences in the hiring process?

3. Does your district account for other types of diverse teaching experiences? If so, how and why? What types of experiences are counted?

4. How, if at all, do you and your district value international student teaching and diverse teaching experiences?

5. Are there any other topics surrounding hiring teachers, diverse teaching experiences, or international student teaching that you would like to discuss?

Data were collected via recording and hand-written notes by the researcher then transferred to a Tape-Based Abridged Transcript (Kruger \& Casey, 2000) by the researcher. Data from the abridged transcript were organized and analyzed using both NVivo software and a Long-Table Approach (Krueger \& Casey, 2000). Trends and patterns were coded and analyzed both within role alike groups representing each type of participate (superintendent, assistant superintendent, and human resource director), and across the role alike groups representing the participants collectively.

\section{Findings}

Findings from this study demonstrated that all participant administrators believed that student teaching abroad is a valuable experience that has an effect on the lives of teachers and ultimately the students whom they teach. The most common words participant administrators used to express this value were "transformative" and "life changing experience." Furthermore, all participant administrators self-identified as having had a teaching or academic experience abroad and valued that experience. Although such experience was not a requirement for participating in the study interviews, it is noteworthy that administrators who had the abroad experience responded. When asked why they chose to participate, all answered that their abroad experience had been meaningful to their professional development as educators and, because of this, they wanted to contribute to this study. 
There were minimal and inconsequential differences in the opinions of participants both within role alike groups and across all roles.

Increased Cultural Awareness

Participant administrators also indicated that student teaching abroad increases cultural awareness and understanding as well as ability to differentiate instruction for diverse learners more so than student teaching in the United States. One participant summarized that, "From student teaching abroad, teachers develop the skill to respond to diversity in students better than teachers who have only taught in America...they understand and can better meet the needs of our students". Words most frequently mentioned by participants included "empathy", "understanding", and "student-centered". Increased Confidence

Participant administrators noted that teachers who have student taught abroad are "more confident in their ability to differentiate instruction than teachers who have not had abroad experience". They opined that this confidence developed because teachers had to "develop new perspectives and adjust to a new culture" in order to "meet the needs of the students whom they taught in very different places".

Increased Ability to Self-Reflect and Improve Professional Practice

Participant administrators indicated that teachers who have student taught abroad "seem to be better equipped than teachers who have taught in the United States to self-reflect and make change to their professional practice." All participants agreed that teachers brought this skill into their subsequent teaching positions and that this practice has helped them to "have greater success as they transitioned into the district" and "deliver better instruction". Long term, participants noted that teachers who student taught abroad tended to "have consistently high evaluations".

Lack of Means to Account for International Experience in the Hiring Process 
While participant administrator comments reflected their beliefs that international student teaching is valuable to the lives of teachers and the education of their students, they had much less to say about how such experience is accounted for in the hiring practices in their districts. When asked whether international student teaching is accounted for differently than American student teaching in the hiring practices in their districts, 29 of the 30 participants indicated that it was not although all 30 participants expressed that "international student teaching experience should be accounted for differently in hiring". When asked why their districts did not account for such international experience, participants struggled to come up with answers. Some said they "didn't know" while others claimed that their districts "had never done it that way" and others stated they didn't know how they "would account for international student teaching experience any differently than other diverse teaching experiences". One administrator had a firmer answer and responded that it "would be against state code to count international experience any differently than any other type of teaching experience".

The one administrator who indicated that his district accounts for student teaching abroad noted that his district also accounts for teaching abroad and the length of time a teacher taught abroad. All of these experiences are accounted for through points on the hiring rubric. This international experience is accounted for separately, and in addition to, teaching experience in the United States. The location of the administrator's district, on the west coast, has "a significant population of teachers who apply having taught abroad" and "our district had to develop a way to account for it". The administrator believed that this location "makes [them] especially aware and appreciative of teachers with international experience because [they] have an international student and family population".

\section{Means of Accounting for Diverse Student Teaching Experience Relational to the District}

While most of the administrators had no formal way for accounting for international student teaching experience, all did have a way to account for diverse student teaching or teaching experience. When asked why, responses suggested that their districts value student teaching and teaching 
experiences in areas with diverse populations; but primarily if that diversity mirrored the diversity in their own districts.

Administrators in urban areas indicated that their district accounted for student teaching and teaching experience in urban areas. One administrator's comments were reflective of others' comments as he stated, "When a student teacher or teacher has experience in an urban setting that is similar to ours, and they are successful in that setting, then I'm more confident that they will be successful in my district as well." The same was true for administrators in rural areas. Socioeconomically, districts that had a higher instance of poverty (greater than $50 \%$ of students on free and reduced lunch) sought student teachers or teachers with experience in areas with poverty. Likewise, administrators also indicated that their districts accounted for student teaching and teaching experience with populations that were racially and ethnically similar to those in their districts. Administrators cited that successful experiences with similar populations were indicative of potential success in their districts. They came from districts with a range of poverty from moderate to acute and in areas with racial diversity in terms of higher populations of African American, Latin, and Asian students. One stated, "When a teacher has already taught students and worked with parents who are Asian, they have a better understanding of the culture." Another indicated that through experience with a Latinix population, teachers could "come to understand family expectations" while others in areas with African American families indicated that teacher would "better engage" these minority families.

\section{Discussion}

Findings from this study add to the limited body of knowledge on this subject and align with some findings of Bryan and Sprague (1997), DeVillar and Jiang (2012), and Gaudino and Wilson (2019) in that both teachers and administrators felt that international student teaching experience helps teachers to gain: personal confidence; cultural awareness; and ability to differentiate instruction for diverse learners. This study, along with the study by Gaudino, Moss, and Wilson (2011) and Gaudino and Wilson 
(2019), also found that administrators concur with teachers and student teachers that student teaching abroad helps teachers to improve the ability to self-reflect on professional practice and implement change. This skill is important in the lives of teachers as many states have moved towards a teacher evaluation system based on rubrics by Danielson (2007), Stronge (2009), or Marzano (2012), which place value on teacher reflection to improve practice. Also, it is noteworthy that no administrators in this study, no teachers, and no student teachers in previous studies indicated any drawbacks or negative effects to the teaching and professional practice of teachers as a result of student teaching abroad.

This study also reaffirmed literature surrounding administrators' positive perceptions of the value of teaching in diverse settings (Shively \& Misco, 2012) and student teaching abroad (Shively \& Misco, 2012). Through experience with diverse populations, teachers become more astute about cultural differences and how to serve various groups of students (Darling-Hammond \& Bransford, 2005; Darling-Hammond, 2006; Mule, 2010). This finding expanded on Shiveyly and Misco's (2012) finding with administrators in one state who desired to hire teachers whose experience aligns with unique aspects of their district and population served.

Finally, this study suggests that teachers with international student teaching experience do not have a unique advantage in the hiring process despite their feelings that they do. Administrators do not account for international student teaching experience any differently than any other type of teaching experience, even though they value it more and differently. Teachers with international experience can certainly bring forth that experience in the hiring process but may be more successful if they present it in terms of how the diversity in their international experience relates to the district in which they are applying and how they would use their diverse teaching experience to serve local students (just as was found by Shively \& Misco, 2012). As all administrators who participated in interviews for this study had some sort of abroad learning experience, they may have had a different, and perhaps more positive, perception of international teaching than other administrators who do not have an abroad experience. 
Further study could be aimed at investigating how administrators who do not have international teaching or academic experience perceive and hire teachers with international student teaching experience.

\section{Recommendations}

Universities that offer student teaching abroad programs should continue to do so as such experiences appear to be beneficial to student teachers, however, they need to be realistic about what those benefits are and are not. Student teaching abroad, in and of itself, does not appear to be a helpful factor for teachers in the hiring process unless they are able to discuss such experience in terms of how it makes them a stronger candidate because they can better relate to and teach the unique body of students in that district. Universities should work with their student teachers on job application and interview skills and how those students can best bring forth their abroad student teaching experience as well as other experiences in diverse settings.

Based on accounts from student teachers, university faculty, and school administrators, student teaching abroad improves teachers' abilities to self-reflect on and improve their professional practice. Yet, not every student teacher will have an abroad placement where they are more apt to acquire this skill. Universities should examine how their policies and practice can better assist education majors with developing reflective skills which are important to their professional practice. University supervisors and cooperating teachers are in a key position to assist teacher candidates with developing the skill of selfreflecting to improve professional practice.

\section{Conclusion}

International student teaching placements make a difference in the lives of teachers and the students and schools that they serve. This experience brings with it a necessity for the student teacher to embody ethnorelativism; for, after all, when one is immersed in another land, one must participate in that culture if for no other reason than simple survival. If having such ethnorelativism was important 
only in the foreign land, it would remain there when the student teacher came home to the United States. However, by a multitude of accounts of student teachers who have student taught abroad, their abroad experience was a life changing experience in which they learned how to self-reflect deeply on their professional practice to improve their teaching, interact and be comfortable and confident with those from other cultures, and in doing so developed a level of self-confidence never before felt from their American-based placements even if those placements were with diverse populations. These student teachers brought these attributes home because they had become woven into the fabric of their being and professionalism.

As districts seek to prepare their students for an increasingly global society, future research could investigate how districts can account uniquely for global teaching experiences. Through such experiences, teachers become more global citizens with demonstrated conviction to bring this experience to their classrooms. Such role modeling does not bring reform to teaching; for to reform is to change what exists. Instead, teachers with global vision bring new forms to their students to prepare them to adapt and lead their future world.

\section{Author Note}

Ann C. Gaudino, Ed.D. is an Associate Professor of Education and Educational Leadership at Millersville University of Pennsylvania. Prior to this appointment, Dr. Gaudino was an Associate Professor at West Liberty University, West Virginia and served for 21 years as a school district assistant superintendent, human resource director, and school principal and teacher. Dr. Gaudino can be reached at ann.gaudino@millersville.edu 


\section{References}

Bennett, M. J. (1986). A developmental approach to training for intercultural sensitivity. International Journal of Intercultural Relations, 10(2), 179-196.

Bennett, M. J. (1993). Towards ethnorelativism: a developmental model of intercultural sensitivity. In M. Paige (Ed.), Education for the intercultural experience (2nd ed.) (pp. 21-71). Intercultural Press.

Bennett, M. J. (2004). Becoming interculturally competent. In J. Wurzel (Ed.), Toward multiculturalism: $A$ reader in multicultural education (pp. 62-77). Intercultural Resource Corporation.

Bennett, J., \& Bennett, M. (2004). Developing intercultural sensitivity: an integrative approach to global and domestic diversity. In D. Landis, J. Bennett, \& M. Bennett (Eds.), Handbook of intercultural training (3rd ed.) (pp. 147-165). Sage.

Bennett, J., Bennett, M. \& Allen, W. (2003). Developing intercultural competence in the language classroom. In D. Lange \& R. M. Paige (Eds.), Culture as the core: Perspectives on culture in second language learning (pp. 114-116). Information Age Publishing.

Bradley, R., Quinn, S. \& Morton, M. L. (2009). Consonance and dissonance in a study abroad program as a catalyst for professional development of pre-service teachers. Teaching and Teacher Education, 25, 525-532.

Bryan, S. L., \& Sprague, M. M. (1997). The effect of overseas internships on early teaching experiences. The Clearing House: A Journal of Educational Strategies, Issues and Ideas, 70(4): 199-201.

Creswell, J. (2014). Research design: Qualitative, quantitative, and mixed methods approaches. SAGE. Danielson, C. (2007). Enhancing professional practice: A framework for teaching (2nd ed.). Association for Supervision and Curriculum Development.

Darling-Hammond, L. (2006). Powerful teacher education: Lessons from exemplary programs. JosseyBass. 
Darling-Hammond, L., \& Bransford, J. (Eds.). (2005). Preparing teachers for a changing world. JosseyBass.

DeVillar, R., \& Jiang, B. (2012). From student teaching abroad to teaching in the U.S. classroom: Effects of global experiences on local instructional practice. Teacher Education Quarterly, Summer, 724.

Gaudino, A., Moss, D., \& Wilson, E. (2012). Key issues in international clinical experiences for graduate students in education: Implications for policy and practice. Journal of International Education and Leadership, 2(3), 1-16.

Gaudino, A., \& Wilson, E. (2019). The long-term effects of international student teaching placements. Journal of Comparative and International Higher Education, 11(Spring), 22-29. https://www.ojed.org/index.php/jcihe/article/view/927

Glaser, B., \& Strauss, A. (1967). The discovery of grounded theory. Aldine.

Kissock, C., \& Richardson, P. (2009, December 14-17). It's time to internationalize teacher education [Paper presentation]. International Council on Education for Teaching 54th World Assembly, Muscat, Oman. https://educatorsabroad.org/eacontent/articles/223.pdf

Krueger, R., \& Casey, M.A. (2000). Focus groups: A practical guide for applied research (3rd ed.) Sage Publications.

Martin, L. (2012). International student teaching in non-Western countries: Impact on first year teachers [Doctoral dissertation, lowa State University]. Iowa State University Digital Repository.https://lib.dr.iastate.edu/cgi/viewcontent.cgi?referer=https://www.google.com/\&ht tpsredir=1\&article=3406\&context=etd

Marx, H., \& Moss, D. (2011). Please mind the culture gap: Intercultural development during a teacher education study abroad program. Journal of Teacher Education, 62(1), 35-47.

Marzano, R. (2012). Becoming a reflective teacher. Marzano Research Laboratory. 
Morse, J., Barrett, M., Mayan, M., Olson, K. \& Spiers, J. (2002). Verification strategies for establishing reliability and validity in qualitative research. International Journal of Qualitative Methods, 1(2), 13-22. https://journals.sagepub.com/doi/10.1177/160940690200100202

Mule, L. (2010). Teacher education, diversity, and community engagement in liberal arts colleges. Rowman \& Littlefield Publishers, Inc.

Shively, J., \& Misco, T. (2012). Student teaching abroad will help you get a job: Exploring administrator perceptions of international experiences for preservice teachers. The International Education Journal: Comparative Perspectives, 11(1), 52-68.

Stachowski, L., \& Brantmeier. E. (2002, February 2-6). Understanding self through the other: Changes in student teacher perceptions of home culture from immersion in Navajoland and overseas [Paper presentation]. Annual Meeting of the Association of Teacher Educators, Denver, CO. https://files.eric.ed.gov/fulltext/ED465715.pdf

Strauss, A., \& Corbin, J. (1990). Basics of qualitative research: Grounded theory procedures and techniques. Sage.

Stronge, J. (2002). Qualities of effective teachers. Association for Supervision and Curriculum Development.

Wilson, E. (2009). Curry in Cambridge: The first year. Northeastern Educational Research Association Conference Proceedings, 2009, Paper 32. http://digitalcommons.uconn.edu/cgi/viewcontent.cgi?article=1032\&context=nera_2009

Wilson, E., \& Flournoy, M.A. (2007). Preparing students for the intercultural experience: Orientation and training. In K. Cushner \& S. Brennan (Eds.), Intercultural student teaching: A bridge to global competence (pp. 1-12). Lanham, Rowman \& Littlefield Education. 